\title{
GESTÃO E SAÚDE MENTAL: PERCEPÇÕES A PARTIR DE UM CENTRO DE ATENÇÃO PSICOSOCIAL ${ }^{1}$ MANAGEMENT AND MENTAL HEALTH: PERCEPTIONS FROM A PSYCHOSOCIAL CARE CENTER GESTIÓN Y SALUD MENTAL: PERCEPCIONES A PARTIR DE UN CENTRO DE ATENCIÓN PSICOSOCIAL
}

\author{
Rita Maria Heck², Valquíria de Lourdes Machado Bielemann³, Teila Ceolin ${ }^{4}$, Luciane Prado Kantorski², \\ Janaina Quinzen Wilhich ${ }^{4}$, Fabieli Gopinger Chiavagatti ${ }^{5}$
}

${ }^{1}$ Estudo financiado pelo Ministério da Saúde e Conselho Nacional de Desenvolvimento Científico e Tecnológico, através do Edital 07/2005.

${ }^{2}$ Doutora em Enfermagem. Professor Adjunto da Faculdade de Enfermagem e Obstétrica da Universidade Federal de Pelotas (UFPEL). Rio Grande do Sul, Brasil.

${ }^{3}$ Mestre em Enfermagem. Professor Adjunto da Faculdade de Enfermagem e Obstétrica da UFPEL. Rio Grande do Sul, Brasil.

${ }^{4}$ Mestranda em Enfermagem do Programa de Pós-Graduação em Enfermagem da UFPEL. Rio Grande do Sul, Brasil.

${ }^{5}$ Acadêmica de Enfermagem do $7^{\circ}$ semestre da UFPEL. Bolsista da Fundação de Amparo a Pesquisa da UFPEL. Rio Grande do Sul, Brasil.

PALAVRAS-CHAVES: Saúde mental. Avaliação. Políticas públicas. Enfermagem.
RESUMO: A pesquisa avalia a gestão do serviço de saúde mental de um município da região sul do Brasil a partir da percepção de usuários, familiares e profissionais vinculados ao Centro de Atenção Psicossocial. Consiste num estudo de caso, de abordagem qualitativa, os dados foram coletados no mês de outubro de 2006, sendo entrevistados 11 usuários, 12 familiares e 21 profissionais da equipe de saúde. A análise dos dados seguiu a avaliação de quarta geração através do agrupamento por núcleos temáticos. O conteúdo destas informações teve validação nos respectivos grupos e a pedido dos envolvidos negociados com o gestor municipal. Entre os pontos de negociação se destaca a importância de uma sede própria para o Centro de Atenção Psicossocial, a presença física do secretário de saúde nas atividades do serviço e um reconhecimento de que a gestão municipal acolhe as demandas de saúde mental.
KEYWORDS: Mental health. Evaluation. Public policies. Nursing.

PALABRAS CLAVES: Salud mental. Evaluación. Políticas públicas. Enfermería.

\begin{abstract}
This study evaluates mental health care management in a southern Brazil municipality from the points of view of its users, their families, and professionals linked to the Psychosocial Care Center. It consists of a qualitative case study, using data collected in October, 2006, through interviews with 11 users, 12 relatives, and 21 health care team professionals. Data analysis followed fourth generation evaluation through grouping by thematic nuclei. The information content was validated in respective groups and, per request of those involved, negotiated with the county administrator. Among the negotiated issues to be highlighted was the importance of the Psychosocial Care Center having its own headquarters, the physical presence of the Health Department Secretary, and the acknowledgement that county administration embraces the demands of mental health requirements.
\end{abstract}

RESUMEN: En el estudio se evalúa la gestión del servicio de salud mental a partir de la percepción de los usuarios, familiares y profesionales pertenecientes a un Centro de Atención Psicosocial, de un municipio situado al sur del Brasil. Es un estudio de caso, con enfoque cualitativo, cuyos datos fueron recolectados en el mes de octubre de 2006. Para el estudio se entrevistaron 11 usuarios, 12 familiares y 21 profesionales del equipo de salud. Al análisis de los datos se siguió con la evaluación de la cuarta generación a través de su agrupación en grupos temáticos. El contenido de esas informaciones fue validado en sus respectivos grupos, y a pedido de los participantes, fue presentado para la gestión municipal. Entre las cuestiones objeto de la negociación se pueden destacar: la importancia de un lugar adecuado para el Centro de Atención Psicosocial, la presencia del secretario de Salud en las actividades del servicio, y un reconocimiento de que la gestión municipal acoge las demandas sobre la salud mental
Rita Maria Heck

Endereço: Padre Anchieta, 1333, ap. 1001

96015-420 - Pelotas, RS, Brasil

E-mail: feo-pos@ufpel.tche.br
Artigo original: Pesquisa Recebido em: 15 de abril de 2008 Aprovação final: 12 de novembro de 2008 


\section{INTRODUÇÃO}

Discutir gestão no contexto do Sistema Único de Saúde (SUS) é um processo complexo, especialmente quando o foco é a avaliação de um serviço de saúde mental, no caso específico os Centros de Atenção Psicossocial (CAPS), que pode ser identificado como um "novo serviço", pois veio para romper com o modelo anterior centrado no hospital reproduzindo as práticas de isolamento, segregação, exclusão e submissão à autoridade. Nesta perspectiva temos que pensar a gestão como uma ação política com interlocução e avaliação, como um instrumento que requer uma metodologia específica que contemple a pluralidade e a interdisciplinaridade, focando as inter-relações entre subjetividade, gestão dos processos de trabalho e clínica. ${ }^{1}$

Assim, temos que olhar para metodologias que superem a avaliação clássica, onde o pesquisador é o avaliador que aplicando o método científico consegue expressar resultados em números. A avaliação participativa traz a necessidade de incluir os diversos atores envolvidos nos serviços, a consideração de diferentes valores e pontos de vista, e uma preocupação para que os resultados da pesquisa sejam negociados com os atores no sentido de encontrar saídas para os problemas concretos que vem sendo identificados.

Neste contexto, a avaliação de serviços inseridos no novo modelo de atenção psicossocial requer instrumentos e metodologias que promovam um olhar sobre a subjetividade, e a complexidade das novas práticas de atenção.

Os sistemas de saúde de muitos países, inclusive o do Brasil, têm passado por importantes reformas que buscam melhorar não apenas sua relação custo-benefício, mas, principalmente, a cobertura da atenção básica, a gestão descentralizada, a melhora na qualidade do cuidado e o aumento da participação da comunidade. ${ }^{2}$

Tais mudanças têm atingido todo o sistema de saúde brasileiro, especialmente a saúde mental, que nos últimos cinqüenta anos tem vivido um movimento mundial de reversão do modelo manicomial impulsionado a partir da Conferência de Caracas para Reestruturação da Assistência Psiquiátrica na América Latina. Este movimento desencadeou importantes experiências alternativas e iniciativas regionais que estão transformando as organizações, sua operacionalidade, e principalmente, a ideologia e os paradigmas conceituais que os sustentam. ${ }^{2}$

A implantaçãoSUS, tem parte de seu sucesso relacionado a gestão e a organização das práticas dos serviços de saúde, específicos a gestão dos recursos humanos. Esse processo representou para a história da saúde pública no Brasil uma inovação, tanto no campo das políticas de saúde quanto na macropolítica de reforma do Estado.

A desistitucionalização prevista na reforma psiquiátrica implica em ampliar o conceito de cidadania, no sentido de admitir a pluralidade dos sujeitos com suas diferenças e diversidades, colocando-os no mesmo patamar de sociabilidade e dando-lhes o real direito ao cuidado, para que possam receber ajuda em seu sofrimento, sua positividade e em sua possibilidade de sujeito de desejos e projetos. ${ }^{3}$

Neste contexto, começou a construção de uma rede de atenção em saúde mental que pudesse suprir as necessidades de cuidado do portador de sofrimento psíquico e assim substituir a assistência/desassistência prestada pelos hospitais psiquiátricos. Os CAPS surgiram como uma proposta de cuidado mais adequado aos princípios e diretrizes do processo de Reforma Psiquiátrica.

As políticas públicas em saúde mental vigente no País, dispõem sobre os direitos do indivíduo e redirecionam o modelo assistencial em saúde mental. Os estados e municípios devem realizar uma política de saúde mental equânime, inclusa, extra-hospitalar com base comunitária. Os gestores devem possibilitar condições técnicas e políticas que garantam o direito ao tratamento, a organização de uma rede de atenção integral a saúde através de dispositivos sanitários e sócioculturais que integram várias dimensões da vida do indivíduo. Esta lógica de rede deve fazer com que os CAPS sejam dispositivos estratégicos, capazes de funcionar como centros articuladores das instâncias dos cuidados básicos de saúde, incluindo estratégia de saúde da família, rede de ambulatórios, atendimento terciário, atividades de cuidado e suporte social.

Neste artigo temos o objetivo de apresentar os resultados referentes à política pública de gestão para inclusão social, realizada em um município do Rio Grande do Sul, investigando um CAPS. As informações fazem parte da pesquisa avaliativa mais ampla denominada: Avaliação dos Centros de Atenção Psicossocial da Região Sul do Brasil (CAPSUL).

\section{METODOLOGIA}

Consiste numa pesquisa do tipo estudo de caso. A avaliação qualitativa de CAPS foi um estudo desenvolvido em cinco municípios, a partir 
da avaliação construtivista, responsiva e da abordagem hermenêutico-dialética.

O estudo de caso é uma investigação empírica que aborda um fenômeno contemporâneo dentro de seu contexto de vida real, visando apreender uma situação tecnicamente única baseando-se em várias fontes de evidência, com os dados convergindo num triângulo e beneficiando-se do desenvolvimento prévio de proposições teóricas, que visam conduzir a coleta e análise dos dados. ${ }^{4}$

A avaliação de quarta geração norteou o processo teórico-metodológico da pesquisa. ${ }^{5-6}$ Os instrumentos de coleta de dados foram documentos como o projeto terapêutico do serviço, entrevistas com equipe, usuários e familiares e observação do CAPS. Ancorada nesta metodologia mergulhamos no objetivo de apreender a dinâmica do serviço, a forma como os atores interagem e os sentidos construídos pelos mesmos em sua relação com sua prática. Junto com isso, manteve-se a preocupação em realizar uma avaliação que pudesse ser também dispositivo, possibilitando que grupos de interesse ampliem a capacidade de intervirem sobre a realidade do serviço.

A etapa qualitativa do estudo de avaliação CAPSUL concentrou-se em CAPS I e II, de cinco municípios da região sul do país, desenvolvida na forma de estudo de caso, são eles: AlegreteRS, Joinville-SC, São Lourenço do Sul-RS, Porto Alegre-RS, Foz do Iguaçu-PR. Lembrando que as informações deste artigo são específicas do município deSão Lourenço para o qual foi convencionado o caso número três. Seguindo esta lógica de sigilo e anonimato, os informantes foram identificados pela letra E para a equipe, U para usuários e F para familiares seguidas do número do município e de cada participante, ex.(E[3]5).

O projeto de pesquisa de Avaliação dos CAPS da região sul do Brasil foi apreciado e aprovado (protocolo 074/05) pelo Comitê de Ética em Pesquisa da Faculdade de Medicina da Universidade Federal de Pelotas. Todos os entrevistados concordaram em participar da pesquisa e assinaram o Termo de Consentimento Livre e Esclarecido.

As informações de subsídio para a elaboração deste artigo foram coletadas por cinco pesquisadores que realizaram o trabalho de campo intensivo, neste município no mês de outubro de 2006. Esta equipe gerou informações registradas em diário de campo decorrente da observação do CAPS e da rede de Saúde, com enfoque na atenção em saúde mental, computando um total aproximado de 150 horas cada. Além disto, foram reali- zadas 11 entrevistas com usuários, 12 entrevistas com familiares e 21 entrevistas com profissionais da equipe. Este material foi validado com cada grupo respectivamente. Por solicitação da equipe de profissionais do CAPS na fase de negociação, os resultados também foram apresentados para a gestão do município.

Durante o processo de análise os dados foram transcritos e organizados por estudo de caso. As informações empíricas foram agrupadas por grupos de interesse e decompostas em unidades temáticas, unidades de informação e fragmentos das entrevistas, seguindo a orientação da avaliação de quarta geração..$^{5-6}$ Dentre os marcadores que orientaram a análise da pesquisa, ${ }^{7}$ há os que contemplam questões internas e externas do serviço. Os marcadores internos estão relacionados à avaliação da estrutura, processo de trabalho e resultado, e os externos envolvem as questões relacionadas às políticas públicas, a gestão, a articulação da rede de saúde e a relação da sociedade com o fenômeno da loucura. Este artigo apresenta apenas as informações que emergiram referentes a gestão e a articulação da rede de saúde.

Contextualizando o local do estudo, São Lourenço do Sul-RS, tem uma população total de 43.691 mil habitantes, destes 23.463 mil residem na zona urbana e 20.228 mil na zona rural. ${ }^{8}$

O sistema de saúde municipal é estruturado em 12 Unidades Básicas de Saúde (UBSs), sendo cinco localizados em zona urbana e sete em zona rural (cinco equipes de Saúde da Família); uma Unidade Móvel; uma Unidade Sanitária; um Ambulatório Central e três unidades de Saúde Mental (CAPS-Nossa Casa, CAPS-infantil, CAPS-álcool e drogas). Há ainda dois hospitais, com um total de 153 leitos, sendo 108 destinados ao SUS.

As ações de saúde mental em São Lourenço do Sul tiveram início em 1984, ainda não caracterizado como um serviço, a partir de palestras realizadas na comunidade de cunho preventivo. As negociações evoluíram e em 1988, foi inaugurada a Nossa Casa como espaço de saúde mental. ${ }^{9}$

A rede de saúde mental de São Lourenço do Sul, idealizada pelos profissionais que durante o estudo qualitativo diversas vezes mencionaram a sua trajetória de "mentaleiros", é composta pelo CAPS-Nossa Casa, junto a ela funciona ainda um ambulatório de psicologia e psiquiatria. Além destes, em prédios independentes no espaço urbano, funciona o CAPS-Saci (desde 2005) para a população infantil e o CAPS-Careta (desde 2003) para alcoólatras e drogados. Faz parte da rede a unidade 
psiquiátrica do Hospital de Caridade de São Lourenço do Sul, contando com 10 leitos. Todos estes serviços são cadastrados no SUS, atendem pacientes do meio urbano e rural de São Lourenço do Sul e os referenciados pelos municípios próximos.

A rede de saúde mental funciona de forma articulada, sendo que observamos que há oficinas (exercícios físicos, lazer), participando usuários dos diferentes serviços. Além disso, este movimento de interação extrapola para espaços sociais mais amplos como: secretaria municipal, escolas, famílias, espaços de lazer e da economia (atividade agrícola) tendo em vista o atendimento das demandas de usuários e sua inserção na comunidade local.

A equipe da Nossa Casa é multiprofissional, composta por profissionais que possuem diferentes formações de nível superior e de nível médio.

O CAPS-Nossa Casa mantém uma rotina no acompanhamento dos usuários que a freqüentam de segunda à sexta-feira, alguns em regime integral e outros freqüentam o serviço algumas vezes por semana, ou seja, a modalidade de atendimento pode ser do tipo: intensivo, semi-intensivo e não intensivo. O número de usuários freqüentadores do serviço varia de acordo com o período e o dia da semana, mas pode-se estabelecer uma média diária de 25 a 30 usuários, totalizando 190 usuários.

\section{RESULTADOS E DISCUSSÃO}

A política pública em saúde mental no município de São Lourenço do Sul-RS está de acordo com o que vem sendo proposto a nível nacional de atendimento na comunidade assegurando o respeito aos direitos humanos, que incluem como princípios básicos: o direito a privacidade, autonomia individual e o direito a informação e participação. ${ }^{10}$ Esta opinião emerge entre os diferentes segmentos entrevistados como detalharemos a seguir.

A sensibilidade para este outro modo de cuidar é apontada como uma prática necessária neste contexto, mas acima de tudo o profissional também lembra que a gestão municipal tem um papel singular de compreensão e comprometimento como emerge na entrevista.

[...] aqui tem transporte, tem uma casa que tem um atendimento bom, isso tudo é respaldado pela saúde, pela secretaria da saúde, porque se a secretaria da saúde não dá um respaldo bom para a nossa casa, essa casa não tem condições de sobreviver [...] (E[3]7).

[...] estamos com uma gestão comprometida com a reforma, [...] isso é importante no cuidado, porque no cuidado tu precisa ter recursos, muitas vezes as pessoas não entendem. É muito mais fácil do que tu internar o cara, do que tu ir todos os dias de carro na casa do usuário [...] mas eu não quero internar o cara, eu quero cuidar dele. Não quer ir para o CAPS, está com problema. Então, vamos fazer o CAPS ir até ele. Então, eu preciso ter uma administração que invista nisso. Se o cara for lá pegar, mas gastou, esse paciente gastou tanto de medicação, tantos litros de combustível, tantas horas extras do motorista para ir buscar ele de noite na casa quando chamaram (E[3]12).

Com o apoio da gestão municipal, o profissional tem liberdade de definir os recursos assistenciais de acordo com as necessidades do usuário, mesmo que isto signifique mais custos financeiros. Entretanto, sabe que está apostando na construção de saúde e alternativas de adaptação deste município as possibilidades de tratamento dentro de uma perspectiva de menor sofrimento e reinserção social. Esta experiência se contrapõe à outras realidades, onde se reivindica maior compromisso dos gestores municipais com a atenção em saúde mental. ${ }^{11} \mathrm{O}$ que demonstra a necessidade e importância de uma relação de suporte entre serviço e gestão. Esta atitude de apoio da gestão permite ao trabalhador de saúde envolvido o seguinte comentário: [...] vem suprindo todas as necessidades que o serviço tem. Isso para nós é ótimo, porque a gente fica além de seguro, a gente fica em paz, seguro, tranqüilo, para ficar tranqüilo para continuar trabalhando. Então isso para nós é fantástico. Inclusive as medicações de pacientes, que são as medicações caras, que quando não tem, não vem por solicitação normal, eles tem comprado essa medicação (E[3]5).

Entre os familiares o apoio da gestão municipal é lembrado nas atividades do CAPS-Nossa Casa, mas também sinalizam para uma atividade cultural conhecida por Mental Tchê que acontece anualmente desde o ano de 2005.

Olha eu acho que eles tão, de alguns anos pra cá eles tão bem envolvidos, tão bem, ajudando bastante, colaborando bastante com a causa do CAPS Nossa Casa. Eles fazem o Mental Tchê, é todo início de ano. É um evento que eles fazem pra juntar fundos pra Nossa Casa, no caso, em prol de algum benefício para os usuários usufruir, para alguma viagem que eles vão fazer. É para ajudar a AFAU que é a associação dos familiares e amigos, dos usuários da Nossa Casa, então a prefeitura tem ajudado bastante nesse evento, participando bastante, divulgando bastante (F[3]6).

O Mental Tchê é um evento social, político, cultural e também festivo, organizado em conjunto com os usuários e familiares do CAPS-Nossa Casa que envolve toda a comunidade local. O 
objetivo deste evento é ser um espaço para promover a cidadania e expressão de potenciais da pessoa em sofrimento psíquico, pois este caracteriza-se por um momento de participação e troca, onde todos podem fazer parte do processo decisório. ${ }^{2}$ Esta atividade partiu da iniciativa do Coordenador Geral de Saúde Mental do Município, foi apoiado pela administração e nos dois anos de evento vem sendo um marco que também é lembrado pelos usuários.

[...] desde que eu estou aqui, o único prefeito que eu vejo que ajuda, é esse que está ai, agora, participa. Já veio aqui, tanto que, agora mesmo quando a gente teve na südoktoberfes, estava lá, ele está sempre na volta da gente. Nas festinhas, a esposa dele, sempre aqui com a gente também. No Mental Tchê, está sempre junto com a gente. Na outra gestão, eu já não via, era bem diferente. Eu acho que só o fato dele estar no meio, já é uma grande coisa. Por causa, que nunca ninguém fez esse tipo de privilégio, desde que eu entrei aqui. Eu me trato aqui, faz oito anos, mais, sete, oito anos por ai. Está sempre junto [...] Pergunta como é que a gente está, se o serviço é bom, pergunta se a gente está bem de saúde, tudo assim, brinca com a gente, e a gente gosta dele aqui (U[3]2).

No depoimento o usuário deixa explícito que a gestão municipal realiza uma atenção diferente da que vinha sendo dado pelos governos anteriores. Esta proximidade por parte dos usuários é relatada em relação à pessoa do prefeito e aproximação com Secretário de Saúde não acontece, parece que este está ausente nas lembranças do usuário.

Vem o prefeito vem, eu fui conhece ele agora. Eu gosto, ele vem seguido ai nos aniversário, nos eventos que tem na casa, ele vem ai, e o secretário eu nem sei quem é talvez eu conheça, mas nem sei quem é (U[3]5).

O apoio da gestão também é lembrado pelas famílias que acentuam a importância de acesso aos medicamentos para quem está em acompanhamento na saúde mental: [...] O remédio para os doentes mentais, tudo sai dali, da prefeitura, a prefeitura é que, é o que dá o remédio, inclusive a minha sempre tem, a minha nunca falta (F[3]1).

Até porque numa reunião que eu fui, foi uma farmacêutica lá da prefeitura para explicar os negocio dos remédios, como que tem que tomar, qual o remédio, é que eles dão os remédio, assim durante o mês, todos os remédio [...] até teve uma palestra, ela conversa. [...] chega lá e pede receita, a médica dá receita, vêm com um monte de remédio para casa, é muito bom, nunca fiquei sem remédio [...]. Conheço, conheço o prefeito, mas a gente quase nem vê ele, muito difícil (F[3]3).

Os familiares dos usuários entrevistados também apontam a pouca expressão do Secretá- rio de Saúde no atendimento cotidiano de saúde mental, mas assinalam que através da gestão tem conhecimento do SUS e em específico tiveram informações sobre o auxilio da Lei Orgânica da Assistência Social. Esse benefício de prestação continuada assegura recursos financeiros para usuários de saúde mental incapacitados para o trabalho podendo ser permanente ou temporária, dependendo do problema enfrentado.

[...] Não, eu não tenho nada o que dize delas, quando eu quero remédio eu vou lá busca, elas me dão, então não tem, quando tem elas dão. Me dá um monte de coisa e nunca peço nada pra ele [...] fui conhece o prefeito agora ha poucos dia. O secretário da saúde eu acho que, como éo nome que eu posso dizer que eu não conheço, eu quase não converso lá para cima com esses (F[3]5).

Contextualmente o que observamos durante o trabalho de campo no município de São Lourenço do Sul, é que há um comprometimento municipal com a implantação progressiva do SUS através de ações na saúde coletiva, como a ampliação das Equipes de Saúde da Família (ESF) no espaço rural, a adstrição da clientela ao território das UBSs no espaço urbano e concomitante a isso a organização da assistência na saúde mental em rede como foi descrito anteriormente. O hospital geral compõe um dos cenários de atenção curativa interligado ao sistema. A rede de saúde mental existe e funciona. A gestão municipal, através da contratação de profissionais, da aquisição do medicamento, da estruturação de espaços físicos a exemplo do CAPS-Nossa Casa, viabiliza a relação serviço-população e fortalece as características comunitárias de solidariedade, de não abandono e internação, como podemos acompanhar no relato, porém não em hospital psiquiátrico.

[...] é o acolhimento vinte e quatro horas, que dentro da nossa rede. Ela é feita a qualquer hora, pela emergência do hospital. É a possibilidade, que nos períodos em que a casa não está em funcionamento, se estabeleça que o uso do espaço do hospital, como um espaço de acolhimento, também pra demanda dos usuários né, [...] essa usuária foi ao hospital, com uma preocupação muito grande, de que ela achava que o filho da filha tivesse morrido, né, [...] ela com essa preocupação, uma coisa delirante, vai no hospital, a técnica de enfermagem acolhe, faz uma ligação pra mim, e eu entro pelo telefone com esse usuário, tranqüilizo ela, digo que não tinha acontecido nada disso, isso eram dez horas da manhã de domingo Então isso, essa vamos dizer assim adaptação é, essa possibilidade de estar vinte e quatro horas, com algum tipo de dispositivo dá uma característica de atendimento diferenciado no CAPS (E[3]12). 
O trabalho em rede é uma recomendação fundamental para serviços comunitários que desejam superar o modelo hospitalocêntrico de assistência psiquiátrica. No SUS, o CAPS na saúde mental e a ESF na saúde em geral, funcionam como porta de entrada. ${ }^{13}$ No interior da rede social da micro-organização territorial deve funcionar de forma articulada e solidária voltado para a proposta de políticas públicas de não abandono ao usuário. Conforme a portaria No 336/02 do Ministério da Saúde no contexto da reforma psiquiátrica brasileira, os CAPS têm a responsabilidade de capacitar, supervisionar e elaborar programas de saúde mental junto às equipes de atenção básica e outros serviços. ${ }^{14}$

Entre os profissionais que atuam no CAPSNossa Casa de São Lourenço do Sul-RS alguns percebem os desafios que estão a frente.

[...] mas eu acho ainda que o que nos falta é nós saíamos mais daqui (do CAPS) e irmos até essas unidades, né, destacar qual o nosso papel (E[3]13).

A interligação entre a rede de cuidados em saúde mental e as equipes de Atenção Primária, mais especificamente da ESF é algo complexo e que apresenta descontinuidades, desafios que são verbalizados pelos profissionais.

[...] porque aquela unidade básica é onde o cara chegou com um [...] problema de mental, manda para o serviço da saúde mental. Então, o que está acontecendo? Nossas unidades não estão funcionando. O que nós vamos fazer? Vamos achar a partir daí uma abertura para a entrada da saúde mental na rede básica. [...] A grande maioria dos nossos técnicos (ligados a saúde mental), estão fazendo pós-graduação de PSF. Então, esse casamento tem que dar certo. [...]. Se este PSF não se sentir bem ligado a equipe, tu crias maior demanda, tu crias uma forma de aumentar o encaminhamento ao serviço de saúde mental, não é a porta. Ela tem que ser o seguinte, tem que trabalhar numa consultoria, tem que trabalhar numa ligação de fazer junto, que é o que a co-responsabilidade, é a responsabilidade compartilhada (E[3]12).

A noção de responsabilidade no campo da saúde mental consiste num processo de negociação, divisão e delegação de encargos entre profissionais, familiares, usuários e membros da comunidade que se vinculam ao portador de transtorno mental. Estes são convidados de diferentes maneiras a tomar para si uma parcela do encargo da assistência, formando redes de suporte social em que se procura construir outro destino social para a pessoa em sofrimento diferente da internação ou abandono. ${ }^{15}$
Nesse processo de responsabilização alguns profissionais do CAPS já conseguem ser referência concretizando esta articulação de forma criativa e peculiar como emerge no comentário: [...] o que nos diferencia dos outros serviços eu acho que é justamente a parte do acompanhante terapêutico, que é a parte que tem o cuidar, sabe? Do, do, do usuário. É o pessoal que está todos os dias com eles, que tem aquela, aquela visão do, do momento, do, do, do dia, do todo, sabe? Temos também é, um bom vínculo com a rede básica. Os PSFs também, alguns encaminhamentos pra gente, alguns encaminhamentos nossos também pra eles (E[3]1).

Permeando esta realidade existe a gestão que investe na capacitação de recursos humanos e qualificação dos técnicos, como verbaliza o entrevistado: [...] bastante investimento na área da capacitação dos..., na valorização dos profissionais assim, eu acho (E[3]12).

A participação da gestão na saúde mental em São Lourenço do Sul-RS deixa poucas lacunas em relação a melhorias que poderiam ser realizadas atendendo expectativa de usuários, familiares e técnicos. Entretanto, observamos que entre os sujeitos do estudo foram pontuadas algumas expectativas em que se salienta uma sede própria para o serviço CAPS-Nossa Casa para maior qualidade das ações terapêuticas. Essa melhoria foi apontada pelos familiares: Porque eu acho que, eles lá, eles lá, sobre este lado de melhora, a só ser que nesse meio tempo o governo de uma verba melhor pra eles. Eles que tem vontade de ter uma casa própria, deles, que lá é alugado, de repente o governo, dê uma verba melhor que eles possam compra um terreno, fazer a casa própria deles (F[3]1).

Os profissionais da equipe reforçam a importância de uma sede própria para o CAPSNossa Casa: [...] nós passamos por vários prédios, aqui já é a quarta casa. Eu vejo hoje o que resolveria né, o atendimento, assim o projeto a localização, que a prefeitura construísse um prédio pra acolher a Nossa Casa (falando do CAPS) (E[3]21).

Percebemos que as deficiências estão voltadas para necessidades do cotidiano de quem tem uma vivência intensiva no CAPS-Nossa Casa, tem uma referência de identidade com o espaço do qual já se apropriou como parte da vida. Neste contexto os profissionais da equipe também apontam demandas para com a contratação de recursos humanos que ajudariam a qualificar o serviço prestado.

[...] então eu acredito assim, que não tem como não ter um enfermeiro, né, até pela segurança do pessoal, que são técnicos e auxiliares, é muito importante essa presença desse profissional dentro do serviço (E[3]9). 
[...] o nosso enfermeiro que tem que vim [...] e uma coisa que eu acho importante para nós seria manter um terapeuta ocupacional, até pra nos ajudar a organizar as atividades que tem certos usuários assim que não que pode propor, tu pode [...] (E[3]8).

A falta de algum profissional compromete a bom andamento e a qualidade do serviço organizado em equipe, como emerge no relato: [...] não está no nome da coordenação, mas no fundo é ela, assim, depois ela é uma pessoas que ela vem aqui ela organiza né, mas ela está muito lá embaixo (na parte inferior do piso da casa onde funciona o CAPS) pelo fato de ela ser a professora de educação física e também toca ali junto das oficinas [...] (E[3]7).

Em síntese a avaliação apontou que a gestão municipal em São Lourenço do Sul-RS está comprometida, envolvida e num momento ímpar de acordo com os usuários tem se aproximado com sensibilidade da realidade de quem está em sofrimento mental. O conjunto de depoimentos leva a acreditar que é um momento histórico, de motivação e solidificação de que a rede de saúde mental é um fato concreto. A participação da gestão municipal contribui com a cidadania da pessoa em sofrimento mental numa construção diária, norteada para a emancipação do ser humano numa perspectiva de desenvolvimento sustentável.

\section{NEGOCIAÇÕES E CONSIDERAÇÕES}

Frente à proposta metodológica do estudo qualitativo de quarta geração, ${ }^{5}$ aconteceram para a validação da pesquisa cinco encontros totais. Em todos os encontros foram utilizados: apresentações dos dados, debates, reflexões e negociações de ações a serem desenvolvidas em curto, médio e longo prazo, a fim de atender as demandas e necessidades provenientes da préanálise dos dados, na perspectiva de encaminhamentos e da resolubilidade.

O primeiro encontro realizado no CAPSNossa Casa foi frente aos usuários do serviço, o segundo com a família e o terceiro foi realizado com a equipe. Sendo que o quarto encontro foi um momento diferenciado. Por solicitação da equipe, realizou-se uma apresentação com os dados avaliativos dos segmentos de usuários e família, objetivando a troca de saberes oriundos da pesquisa, para que os profissionais deste serviço pudessem se apropriar destas informações e buscarem transformações, frente ao contexto dos acontecimentos. Assim, os profissionais podem procurar cada vez mais a qualificação do serviço e a satisfação dos envolvidos, dentro de uma perspectiva que condiz com os princípios da reforma psiquiátrica.

$\mathrm{O}$ quinto encontro ocorreu com os gestores de saúde do município. Neste contexto, foram apresentados, os primeiros resultados gerados através dos dados qualitativos dos três segmentos de atenção da pesquisa CAPSUL. Ocorreu um diálogo e negociações, no que se referem às necessidades do serviço, que fossem plausíveis de encaminhamentos pelos gestores, alguns em curto prazo, e outros que poderiam desenvolver-se em aprazamentos maiores. Além disto, nessa negociação houve sensibilização do secretário da saúde para que se faça mais presente no CAPS-Nossa Casa. Este justificou que sua ausência deve-se ao envolvimento com as demandas do cargo, e também porque nesse período ficou mais envolvido com os outros CAPS. Entretanto, comprometeu-se a ficar mais atento a esta questão.

Vários encaminhamentos foram realizados a partir deste estudo, alguns resultados aconteceram, quando a equipe de pesquisadores encontrava-se em campo, e outros quando esta havia concluído esta fase da pesquisa qualitativa.

Houve a contratação de um profissional enfermeiro, com a carga horária de quarenta horas semanais. Sendo que o primeiro profissional contratado para a ocupação deste cargo, o qual estava em período probatório, desistiu em sua primeira semana de atividades profissionais, por motivos pessoais e de contraste com o funcionamento do serviço. Com isso, foi possível observar que um profissional para atuar em um CAPS, deve apresentar um perfil condizente com as necessidades e finalidades do serviço.

Seguidamente, aconteceu uma nova contratação, de uma enfermeira formada pela Faculdade de Enfermagem e Obstetrícia da UFPEL, a qual participou do campo deste estudo. A carga horária deste técnico manteve-se de 40 horas, o que caracteriza a sua identificação com a proposta do serviço e com as atividades realizadas que vão ao encontro do projeto terapêutico.

Referente à adequação de espaços físicos no CAPS, pré-estabelecidos na negociação com a equipe, ocorreu a mudança da oficina de tapeçaria para uma área física que condiz com as necessidades levantadas, sendo que por sua visibilidade permite uma melhor comercialização dos produtos gerados nesta oficina, o que possibilita a inclusão social do usuário na sociedade através do trabalho, para otimizar o requisito geração e renda. Esta readequação agregou a satisfação do 
profissional que atua nesta oficina, corroborando para o fortalecimento dos vínculos frente às relações interpessoais, contemplou assim que todos os sujeitos participassem do processo. Esta mudança demonstrou que o serviço busca a integração de todos os seus atores sociais, o que mostra que há uma linearidade e flexibilidade em suas ações.

Outro ponto da negociação que emergiu resultado do período das atividades dos pesquisadores e de necessidades sentidas pela equipe, foi a capacitação de conselheiros de saúde no município, implementada pela gestão. Além disto, o secretário de saúde e o coordenador de saúde mental asseguraram que será realizada uma capacitação com os profissionais das equipes da ESF e das UBSs, para discutir e refletir as interligações das redes de assistência à saúde. Para cada vez mais integrar os serviços, na tentativa de realizar ações em que a referência e contra-referência, preconizadas pelo SUS, sejam consideradas no atendimento a saúde da população. Pois para que o atendimento seja integral, é necessário que todos os serviços estejam engajados no tratamento do usuário.

Um ponto que destacamos, e que podemos considerar resultado das negociações foi à contratação de um terapeuta ocupacional, profissional que foi visto pela equipe do CAPS-Nossa Casa, como de grande importância para as demandas organizacionais e funcionais das oficinas terapêuticas.

Outro aspecto ressaltado nas negociações foi a relação do serviço com a família, através de visitas domiciliares e oficinas que abordem questões emocionais e o estresse - sobrecarga do cuidador. Podemos perceber que ocorreu uma reflexão e sensibilização dos profissionais, os quais pretendem desenvolver estratégias para conseguir alcançar este objetivo do serviço, de uma inserção mais plena da família para que esta também seja vista como centro da atenção, e portanto, necessitante de cuidado.

A construção de um modelo de atenção voltado à satisfação das necessidades de saúde, requer uma articulação entre uma dada concepção do processo saúde-doença e um conjunto de práticas, que exige uma consistência interna entre os elementos constitutivos do processo de trabalho - objeto, finalidade, instrumentos e a ação dos trabalhadores - para "efetivamente objetivar-se em um produto". ${ }^{16}$

Esta pesquisa avaliativa com seu modelo metodológico possibilitou a todos os envolvidos a oportunidade da negociação, o que resultou no alcance dos objetivos e de várias demandas percebidas e sentidas pelos usuários, familiares e equipe.
Contudo, temos a certeza que estas conquistas não ocorreram por acaso, pois, desde o início da entrada em campo dos pesquisadores foi percebido e sentido que existiu acolhimento, apoio e flexibilidade de todos os envolvidos. Além disso, todos queriam o melhor para o serviço de saúde mental do município, dando-se ênfase a Nossa Casa dentro do proposto na Reforma Psiquiátrica.

Por fim, compreendemos a importância e a vontade política dos gestores que neste trabalho de pesquisa mostraram-se sensibilizados com as negociações e possuem o entendimento de que é possível ser diferente na assistência ao portador de sofrimento psíquico.

Portanto, é necessário integrar os resultados das novas experiências da prática e as contribuições da ciência nos programas de educação tanto para a formação do enfermeiro, como nos programas de educação continuada para os que atuam na assistência e em programas de pós-graduação.

O bom funcionamento do CAPS-Nossa Casa, mostra uma construção de um modelo de assistência, com uma história que iniciou em 1984, com profissionais e gestores comprometidos com a mudança do modelo assistencial em saúde mental, a qual teve continuidade resultando no serviço de qualidade que existe atualmente. Isso nos mostra que a mudança de um modelo é algo que não se modifica ou impõe-se repentinamente e sim, construído com a participação dos profissionais, gestores, usuários e comunidade. É este apoio do todo e a organização dos serviços em geral de saúde (redes), que contribui para que este modelo de saúde mental neste município seja referência e qualifique-se continuamente.

\section{REFERÊNCIAS}

1. Onocko-Campos RT,FurtadoJP.Entrea saúdecoletiva e a saúde mental: um instrumental metodológico para avaliação da rede de Centros de Atenção Psicossocial (CAPS) do Sistema Único de Saúde. Cad Saúde Pública. 2006 Maio; 22(5):1053-62.

2. Furegato ARF. Avanços da saúde mental e seus reflexos na enfermagem. Rev Enferm USP [periódico na internet]. 2007 Junho [acesso em 2008 jan 10]; 41(2). Disponível em: http:/ / www.scielo.br/scielo. php?script=sci_arttext\&pid=S0080623420070002000 $01 \& \operatorname{lng}=$ en\& nrm=isso.

3. Amarante PD de C, Torre EHG. A constituição de novas práticas no campo da atenção psicossocial: análise de dois projetos pioneiros na reforma psiquiátrica no Brasil. Saúde em Debate. 2001 MaioAgo; 25(58):26-34. 
4. Yin RK. Estudo de caso: planejamento e métodos $3^{\text {a }}$ ed. Grassi D, tradutor. Porto Alegre (RS): Bookman; 2005.

5. Guba EG, Lincoln YS. Effective evolution. San Francisco (USA): Jossey Bass Publishers. 1998.

6. Wetzel C, Kantorski LP. Avaliação de serviços em saúde mental no contesto da reforma psiquiátrica. Texto Contexto Enferm. 2004 Out-Dez 13(4):593-8.

7. Donabedian A. La investigación sobre la calidad de la atención médica. Salud Publica de Ciudad de México (MX): La Prensa Médica Mexicana S.A., 1986.

8. Instituto Brasileiro de Geografia e Estatística [página na Internet]. Cidades. [Acesso em 2007 Jan 10]. Disponível em: http://www.ibge.gov.br/ cidadesat/topwindow.htm?1.

9. Wetzel C, Almeida MDP de. A construção da diferença na assistência em saúde mental no município: a experiência de São Lourenço do Sul/ RS. Saúde Debate. 2001 Maio-Ago 25(58):77-87.

10. Nascimento CLB. Gestão em saúde mental em Camocim-CE. [monografia]. Sobral (CE): Universidade Estadual Vale do Acaraú. Escola de Formação Visconde de Sabóia; 2006.
11. Luzio CA. A atenção em Saúde Mental em municípios de pequeno e médio portes: ressonâncias da reforma psiquiátrica. [tese]. Campinas (SP): Universidade Estadual de Campinas. Programa de Pós-Graduação em Saúde Coletiva; 2003.

12. Willrich JQ, Kantorski LP. Caps Castelo: um pouco da história da loucura em Pelotas. Pelotas (RS): EDUUFPel; 2008.

13. Filho NGV, Nobrega SM. A atenção psicossocial em saúde mental: contribuição teórica para o trabalho terapêutico em rede social. Estudos de Psicologia. 2004 Maio-Ago; 9(2):373-9.

14. Ministério da Saúde (BR). Portaria - GM Nº 336 de 19 de fevereiro de 2002. Define e estabelece diretrizes para o funcionamento dos Centros de Atenção Psicossocial. Brasília (DF): MS; 2002.

15. Silva MBBE. Atenção psicossocial e gestão de populações: sobre os discursos e as práticas em torno da responsabilidade no campo da saúde mental. Physis: Rev Saúde Coletiva. 2005 Jan-Jun; 15(1):127-50.

16. Gonçalves, Mendes. Práticas de saúde: processo de trabalho e necessidades. (Cadernos CEFOR, 1 - Série textos) São Paulo (SP): Centro de Formação dos Trabalhadores em Saúde da Secretaria Municipal da Saúde; 1992 